\title{
The image of the nursing profession as perceived by the community members of three adjacent residential areas of Empangeni in KwaZulu-Natal
}

\author{
P J Kunene, D Phil, University of Zululand, Durban-Umlazi Campus \\ PN Nzimande, D Litt et Phil, University of Zululand, Durban-Umlazi Campus \\ PA Ntuli, B Cur Honours, Ngwelezane Nursing College
}

\section{Abstract}

The study was undertaken out of concern that nurses and the nursing profession project a negative image to the public they serve. Diverse aspects of nursing examined in this study included standards or quality of nursing care and its influence on encouraging clients to utilise health care services, communication, attitudes, expertise, availability at all times and patients'/clients' participation in decision-making.

Nurses are part of the communities they serve. The rationale for the study was that nurses should be alert to perceptions of the communities about the service they provide, whether expressed formally or informally. Survival of nursing as a profession is dependent upon the positive impact it has on consumers in the past, present and the future.
The aim of the study was to discover, through a systematic, scientific inquiry, the positive and negative perceptions that communities have about nursing. An exploratory, descriptive study was done in KwaZulu-Natal on a sample of 50 participants from three adjacent historically Black residential areas (townships) using questionnaires. Findings of the study were contrary to the assumption that nursing has a negative image. All aspects except one were rated very good or good by the majority of the participants. Those who had negative perceptions, though in the minority, highlighted important reasons directed at both the authorities and the nurses. These were used as a basis for recommendations for further improvement of the image of nursing. The area of gross dissatisfaction among the majority was feeling unsafe with nurses getting increasingly involved in unionism, which would lead to abandonment of patients in times of industrial action.

\section{Introduction}

Society recognises nursing as a profession which provides a valuable and essential service for maintenance of the health of the people. When nurses take up nursing, they enter into an unwritten contract with society. Society gives them the mandate to perform nursing which is a social function that carries social responsibility. Society holds certain expectations from members of the nursing profession, based on a relationship of trust (Searle \& Pera, 1995:115). Any form of malpractice by nurses would endanger the safety and welfare of society and thus harm the relationship between the nursing profession and society. The nurses have a duty to uphold high standards of nursing practice which is what society values about nursing. If they fail to meet these standards and expectations, nursing loses its meaning, professional integrity and good image.

The views of society as consumers of health care play a major role in shaping the image of the nursing profession. The future position of the profession depends on impressions that the public have about it and what the nurses do to improve perceptions of the public on the image of the nursing profession. Perceptions of the public may differ from the percep- tions that nurses have about their own profession. Investigating perceptions of the community provides valuable information to nurses and the nursing profession to help them review their nursing activities in order to meet the consumers' expectations.

\section{Background and Literature Review}

Historically, nursing has been regarded as an important job or profession which is actually a vocation or calling. Gourley (1995:2) argues that, though nursing is placed high on the list of priorities, insufficient value is attached to it. He proposes that this might be due to the fact that it is a predominantly female profession. This gives it a low status in comparison to the predominantly male professions, for example, the medical profession. Society tends to place more value on male-dominated jobs or professions. However concern of society about protection of their health and welfare makes nurses a valued asset in the community.

Nursing has gone a long way to change the images of the past 
which include:

- a folk image as mother and nurturer

- a religious image: more of a charitable service than a profession

- a servant image, for example a doctor's handmaiden.

Contemporary nursing portrays the image of a profession which is well-grounded on a broad scientific and technological base. Because of their advanced preparation, nurses are trusted to provide sound health care in Primary Health Care settings acting autonomously and independent of direct supervision. This is supported by Style's (1982) views that nurses should uphold three fundamental attitudes about their profession, namely: social significance, ultimacy of performance as well as collegiality and collectivity.

Medlen (1986:15) and Kalisch \& Kalisch (1987:iv) share the view that the media has a substantial influence on perceptions of the public on the delivery of health care, particularly nursing care. Whilst Gourley (1995) refers to a positive and glamorous image of nursing portrayed by television, Kalisch \& Kalisch (1987:184) found that the public viewed nurses as less intelligent, irrational, individualistic, displaying less nurturance and empathy than their medical counterparts. This finding is contrary to the nurses' professed commitment to "caring" which is the essence of nursing.

Concern for lack of caring in nursing was the rationale for the development of the Cultural Care Theory by Leininger in the 1950s. This theory lays emphasis on the need for nurses to understand cultural universality and diversity in order to provide culture congruent care that accommodates both the folk and professional contexts of health care (Henry, Arndt, Di Vincenti and Marriner-Tomey, 1989:19-20).

Searle (1988:49-56) commended nurses for their courage in identifying their shortcomings and taking steps to rectify that which erodes the development of the profession and the quality of care. However the lack of drive to market their own profession so as to let the nation know of its contributions and achievements as well as how extensive and vital their services are, remains a challenge for nurses. If this challenge is not met, nurses will continue to find themselves acting according to the negative stereotypes that the public has about them, thus helping to perpetuate the untruthful and offensive images about themselves (Dunn, in McCloskey \& Grace, 1990:434).

\section{Problem Statement}

There is a perception from some members of the community that nursing is gradually losing some of its important values which have given the profession a good name. This results in the fear that the profession holds many uncertainties for the future health needs of the public.

Increasing incidences of industrial action/strikes among nurses in South Africa in the 1990s has further tarnished the image of nurses in the public eye. Community members openly express dismay at nurses who leave patients unattended when they withhold their labour in order to apply pressure on the employer or management to succumb to their personal demands (Kunene, 1995:120; Uys, 1992:33; Van Tonder, 1992:29).

\section{Motivation}

Based on the assumption that the community has negative perceptions about nurses and the nursing profession, the researchers were motivated to conduct the study to find out from the community members themselves if indeed this was true, and if so, to detect what causes such an impression.

\section{Research Question}

The study was an attempt to answer the question "What are the perceptions of the community members of three adjacent historically Black residential areas (townships) of Empangeni in KwaZulu-Natal?"

\section{Objectives}

To identify perceptions of the community about the image of the nursing profession in relation to:

- the type and standard of nursing care

- $\quad$ safety of patients/clients in the nurses' hands

- $\quad$ protection of rights of patients/clients by nurses

- implications of unionism in the nursing profession.

\section{Terminology}

Perception: The process of becoming aware of something, for example people, things, events or ideas. In the context of this study, it refers to awareness of how nursing is practised in the area selected for study.

Community: A group of interacting individuals who occupy a certain territory, are united by commonly shared beliefs, values and norms and utilise the same facilities. In this study it refers to people who reside in the three residential areas under study.

Image: Operationally, the term refers to the sum of beliefs, ideas, and impressions that people have of nurses and the nursing profession.

Nursing profession: An organised group of persons who are engaged in providing nursing service to individuals, families and communities in need of health care. The professional ethical code for nurses sets the parameters of acceptable behaviour and guides nursing practice to ensure preservation of a positive image of the nursing profession in the public they serve.

\section{Research Method Research design}

An exploratory, descriptive survey was conducted in three adjacent historically Black residential areas (townships) in Empangeni area of KwaZulu-Natal. The residents of these townships utilise the same health care facilities. Including more than one residential area was done to prevent the bias which might be introduced through an extraneous variable typical of one area, for example transport problems which might limit utilisation of the health care facilities.

\section{Sample and Sampling Method}

A purposive, systematic random sample of fifty (50) participants was selected. This was a small sample size, limited by the social unrest in these townships at the time of data collec- 
tion, hence the authorities advised against spending too much time in the area. The criteria for inclusion in the sample was adults who had first-hand experience with the health services under study, that is the local hospital and satellite clinics, either as in-patient or outpatient. House numbers provided a base for systematic sampling but, because of purposive sampling, only those with participants who fitted the criteria for inclusion were selected.

\section{Ethical Consideration}

Permission was obtained from the Medical Superintendent of the hospital and from the councillors of the areas selected for study. Informed consent was obtained from the participants after explanation of purpose of the study and they were assured of confidentiality. Voluntary participation was emphasised.

\section{The Research Instrument}

A questionnaire comprising both open-ended and closedended questions was designed, guided by the literature review and the objectives of the study. It comprised five (5) sections, namely demographic data, perceptions on standard or quality of nursing care, patients' rights, safety in the nursing profession and the trade unionism in the nursing profession.

Face and content validity of the instrument was assessed by three research experts who agreed that the instrument was suitable and adequate to measure what it was intended to measure. Furthermore the instrument was pre-tested on ten people who fitted the criteria for inclusion in the fourth adjacent residential area which would not form part of the main study. This resulted in minor adjustments and rephrasing of questions which were not clearly understood. Content validity was further ascertained because the responses of the pretest groups were relevant to the intended investigation of perceptions on the image of the nursing profession. Reliability, that is the consistency with which the instrument measures what it is supposed to measure, was ascertained because the responses of participants in the main study were consistent with those obtained during the pre-test.

The instrument was self-administered. The presence of the researcher during completion of the questionnaire enabled her to assist in clarification and further explanation to those who experienced difficulty in reading or understanding the questionnaire which was in English.
Table 1: Age distribution $(n=50)$

\begin{tabular}{|l|l|l|}
\hline Age Group & Frequency & Percentage \\
\hline $18-20$ & 4 & 8 \\
\hline $21-30$ & 13 & 26 \\
\hline $31-40$ & 12 & 24 \\
\hline $41-50$ & 11 & 22 \\
\hline 51 and above & 10 & 20 \\
\hline TOTAL & 50 & 100 \\
\hline
\end{tabular}

FINDINGS

\section{Biographical Data}

Age was considered an important variable because it might influence one's perceptions about an event or situation, determine the frequency to which one has been exposed to a situation as well as the experience gained from such exposure. The age groups are summarised in table 1 which shows that the majority, 26\% (13) were in the 21-30 age group and $24 \%$ (12) were in the $31-40$ age group..

Gender - there were more females than males, 64\% (32) and $36 \%$ (18) respectively. Provision of mother and baby health care services probably accounts for more females than males attending clinics, since the majority were in the child-bearing age.

Frequency of visits to the hospital or clinic and/or previous admission to the hospital

Perceptions develop better from repeated exposure and wide experience of a situation or event. All respondents had visited the health service, $44 \%$ (22) often, (at least once in two months) $32 \%$ (16) sometimes, (range between two to three times a year) and $24 \%$ rarely, (about once a year or less). $80 \%$ (40) had been hospitalised and $20 \%$ had not been hospitalised but had experienced nursing care in the outpatients department or clinics..

Perceptions on the standard or quality of nursing care and nurses' commitment to their work

As indicated in table $2,68 \%$ (34) rated the quality of care as good. This finding tallied with the perceptions of $70 \%$ (35) who felt that nurses were committed to their work because

Table 2: Ratings for statements on nurses and nursing care $(n=50)$

\begin{tabular}{|c|c|c|c|c|c|c|c|c|c|c|}
\hline \multirow{3}{*}{$\begin{array}{l}\text { Statement } \\
\text { Standards/Quality of care }\end{array}$} & \multicolumn{2}{|c|}{ Very good } & \multicolumn{2}{|c|}{ Good } & \multicolumn{2}{|c|}{ Poor } & \multicolumn{2}{|c|}{ Very poor } & \multicolumn{2}{|c|}{ Total } \\
\hline & $\mathrm{f}$ & $\%$ & $\mathrm{f}$ & $\%$ & $\mathrm{f}$ & $\%$ & $\mathrm{f}$ & $\%$ & $\mathrm{f}$ & $\%$ \\
\hline & 14 & 28 & 20 & 40 & 11 & 22 & 5 & 10 & 50 & 100 \\
\hline Communication with patients & 18 & 36 & 22 & 44 & 10 & 20 & - & - & 50 & 100 \\
\hline Attitudes towards patients & 20 & 40 & 18 & 36 & 12 & 24 & - & - & 50 & 100 \\
\hline Sustained professional commitment & 16 & 32 & 19 & 38 & 9 & 18 & 6 & 12 & 50 & 100 \\
\hline
\end{tabular}


they cared for patients/clients whether doctors were available or not, they acted independently and had not been observed to be neglecting patients deliberately. However, 26\% (13) in this group stated that they would be happy to see more commitment demonstrated, especially by the younger generation who were seen to be not as committed as the 'older nurse', for example these participants highlighted that the 'younger nurses' have a tendency to discuss matters pertaining to their personal, social life instead of concentrating on the patient/client's needs.

Amongst the $30 \%$ (15) who expressed perceptions of lack of commitment, diverse reasons were given, for example

- $\quad 18 \%$ (9) believed it was mainly rooted in inadequate facilities, equipment and personnel. This situation was worse in the clinics than in the hospitals.

- $12 \%$ (6)noted that the ideals of nursing were lost and nurses had developed a "carefree" attitude, were more job-oriented than patient/client oriented.

These findings present a challenge to members of the nursing profession to reinstate both the personal and collective commitment to nursing as well as the social responsibility to which they are held accountable.

Feeling encouraged to utilise the health care facilities As indicated in table 3, the majority, $72 \%$ (36), were encouraged to utilise the health care facilities because they were satisfied with the standard of nursing care they received. Twenty-eight percent $(28 \%)$ (14) who were not encouraged expressed concern about lack of facilities including shortage of personnel, poor patient/client care and nepotism. They stated that those who were known to the nurses got the best and prompt treatment which was not given even to those who were seriously ill. The nurses did not bother to explain reasons for this irregularity. This negates the view that impartial care is the core of professionalism. Searle (1988) warns that it is the little things that blot the image of a true professional.

\section{Communication between nurses and pa-} tients

Although the majority $80 \%$ (40) of the respondents (Table 2) rated the communication as excellent and good, there is concern over the $20 \%$ (10) who rated it as poor. They emphasised that:

- $\quad$ nurses explain poorly to patients and the latter leave without a clear understanding of their conditions and treatment

\section{Table 4: Perceptions on patients' safety if nurses increasingly get involved in unionism $(n=50)$}

\begin{tabular}{|c|c|c|}
\hline PERCEPTIONS ON SAFETY & FREQUENCY & PERCENTAGE \\
\hline Very safe & 8 & 16 \\
\hline Unsafe & 16 & 32 \\
\hline Very unsafe & 26 & 52 \\
\hline TOTAL & 50 & 100 \\
\hline
\end{tabular}


on the attitude projected by each member of the profession. The way that professionals practise and speak about their profession exerts an influence on the community.

\section{Patient/Clients participation in decision-making}

The finding reflected in Table 3 is significant since it shows that a significant proportion of the sample (44\%) (22) did not participate in decision-making, yet all the respondents were adults who should have been allowed to exercise freedom of choice on those matters wherein they were capable of making their own decisions. Adults tend to avoid, resist or resent situations where they feel treated like children and being 'talked down to.'

\section{Protection of the patients' rights to continuous, safe care} and respect of their right to privacy and information $68 \%$ (34) felt that the type of nursing care provided could secure patients' rights to continuous safe care (see table 3 ). An equal number were satisfied with respect of their rights to privacy and information. The patients'/clients' right to privacy includes, among others, privacy during interview, examination or treatment. The right to information includes the right to be informed about diagnosis, prognosis, treatment and alternative treatment, as well as the risks involved. Kelly (1985) warns that, for nurses to ignore the patients'/ clients' fundamental rights to privacy and information is both to betray humanity and to invite dissatisfaction.

\section{Display of nurses' expertise in their work}

This important variable is closely linked to the one of patients/clients feeling encouraged to visit the health care facility. The majority, $76 \%$ (38), were satisfied with the expertise that nurses displayed. $24 \%$ (12) who were not satisfied, gave the following reasons:

- nurses have been trained but they seem to lack the commitment to implement what they have been taught

- $\quad$ nurses only display their expertise when the supervisors are around

- lack of facilities and resources retards the nurses' demonstration of their expertise

The researchers concur with the authors who maintain that the image of the nursing profession will only improve when the nurses make their contributions known and when they demonstrate practically to the public that they are worthy practitioners of their delicate profession and nobody can do it better than the nurses themselves.

Perceptions about safety of patients if nurses involve themselves in activities of non-nursing unions

Eighty-four percent (42) participants stated they felt unsafe if nurses got themselves involved with unions (see Table 4). They feared nurses would use the patients to bargain for their needs, they would abandon patients and endanger their lives. They were not happy that they had seen nurses 'toy-toying' in the streets or going on strike. They feared that nurses had moved away from the traditionally perceived commitment The profession seemed to have lost control over its members and trade unions seemed to have taken over in most hospitals. To support this finding, Uys (1992:32) emphasises that it is wrong to make the innocent suffer when nurses pursue achievement of their professional and economic goals.
Another concern expressed was the belief that trade unions are affiliated to political organizations. Since nurses were seen not to be observing political neutrality, it was difficult to be assured of equal treatment and care to all patients regardless of political affiliation.

Sixteen percent (8) of the participants who stated that they felt safe even if nurses were involved in unionism highlighted that they had seen nurses displaying commitment by striving hard to get to work when there were national stay-aways. Some perceived nurses to be hard workers in spite of low salaries which are a major complaint among most employees in health care organizations.

\section{DISCUSSION}

The findings of this research are contrary to the assumption that the community has negative perceptions about nurses and the nursing profession. In all variables except one, responses reflected a positive image of nursing. The exception was the issue of feeling unsafe with the involvement of nonnursing unions in the nursing profession, which was expressed by $84 \%$ (42) of the participants.

It is the opinion of the researchers that nurses should not take comfort in the fact that those who expressed negative perceptions were in the minority. The fundamental principles of nursing demand that nursing should provide total satisfaction to all their patient/clients. One dissatisfied consumer of nursing care tarnishes the image of nursing and the negative image filters through to the family and to the community. Furthermore, the reasons given by the participants who expressed negative perceptions are significant enough to discredit the nursing profession if nothing is done expediently to correct those behaviours and actions.

While the nurses were commended for being available for patients and for their ability to act independently, some participants were concerned about nurses not showing commitment and not displaying excellence, especially when the authorities were not around. Since nurses are generally referred to as the "backbone" of the health care system. particularly in the Primary Health Care or Community Health centres where they operate with no doctors nor direct supervision from management, any 'care-free' attitude, whether real or imaginary, should be abolished. It is also important to note that the blame for lack of commitment is not levelled at the nurses per se. The authorities are responsible for provision of health facilities and resources. Since lack of commitment was partly related to lack of these, it poses a challenge to the authorities.

The participants who expressed concern about the nurses' lack of empathy and respect for human dignity, failure to listen and their unacceptable manner of approach related this to the fact that nurses appeared hurried. Whilst this is unacceptable behaviour by nurses, one needs to consider the conditions under which nurses work in some health care services, for example, handling large numbers of clients in clinics while grossly understaffed. In those circumstances, nurses cannot give full attention, nor compassionate care and emotional support to each and every client. They attempt to apply the principle of fairness, so that all clients get at least 
minimal care. Unfortunately the patients'/clients' right to information suffers in these circumstances.

On the issue of feeling unsafe because of increasing non-nursing union involvement in nursing, it is important to make the community aware that nurses, like other employees, have a right to belong to a union of their choice, in line with the provisions of the Labour Relations Act (No 66 of 1995) as amended. Furthermore, the current professional nursing organization in South Africa, namely the Democratic Nursing Organization of South Africa (DENOSA) has a union wing. It caters for both the professional as well as the socio-economic needs of nurses (DENOSA CONSTITUTION). Since its establishment in 1995, DENOSA has been comprehensively involved in collective bargaining for nurses' employment-related issues.

Patient/clients need the assurance that they will never be left unattended even if there is industrial action. Both DENOSA and the South African Nursing Council have made this commitment on behalf of their members.

\section{Conclusions}

The study revealed that there is no consensus among community members on the image of nursing. Though the sample of 50 subjects is regarded as small and limiting to generalisation, the conclusion drawn is that on the whole, the public has a favourable image about nurses and the nursing profession.

Findings of this research have also revealed that those participants in the minority who perceive a negative image of nursing have numerous reasons which convince them that the nursing profession is not what it is expected to be in terms of provision of quality nursing care, commitment and availability, effective communication and positive attitudes towards clients, expertise and professionalism.

\section{Recommendations}

Improvement of the image of nursing is needed to eliminate the negative perceptions among any members of the community, however few. This should be a joint effort of the employers or management working together with the nurses. Efforts in obtaining health care resources, both human and material, should be increased in order to improve the quality of nursing service and the commitment of nurses to their work. Nurses should demonstrate to the public that they are prepared to render the best care with the minimal resources available. Communication, interaction and listening to patients/ clients should be facilitated through reviewing the staffing patterns in line with patient numbers and patient acuity so that time for emotional support is also calculated when determining staffing needs. It should be emphasised that nurses must not give patients the impression that they are so hurried that they cannot communicate and share information with them. This negates the need for transparency and information sharing which is emphasised by the present government through the Batho Pele (People First) principles of transformation of the Public Service. These principles should be emphasised and form the foundation for nursing practice in all situations.
Patients/clients should be more involved in decision-making through all phases of health care delivery, that is from needs assessment, planning and implementing health care programmes, to monitoring and evaluation. They will thus feel that they are partners in the health care team and therefore share the responsibility for its successes and failures. This applies equally to openness about labour issues that might lead to industrial action as well as openness about plans provided in instances of industrial action, to ensure that patients/ clients feel that they will never be abandoned.

It is important to conduct a similar study in the same geographical area in five or ten-years' time (whichever is more feasible) to compare perceptions on the image of nursing in different periods. The research is also highly recommended for other areas in the province as well as other provinces in South Africa. 
GOURLEY B.M 1995 : The place of nurses in our society today. Curationis Vol. 18 No. 1. March: 2-4.

HENRY B; ARNDT C; DI VINCENTI M \& MARRINERTOMEY A 1989 : Dimensions of Nursing Administration: Theory, research, education. London: Blackwell Scientific Publications.

KALISCH PA \& KALISCH BJ 1987 : The changing image of the nurse. California: Wesley Publishing Company.

KELLY LY 1985 : Dimensions of professional nursing. New York: MacMillan Publishing Company.

KUNENE PJ 1995 : Strikes by nursing personnel: a challenge for nurses in KwaZulu-Natal. University of Zululand: Unpublished Master's dissertation.

MCCLOSKEY JC \& GRACE HK 1990 : Current issues in nursing. St Louis: The CV Mosby Company.

MEDLEN L 1986 : The image of the nurses in the media. Nursing RSA. Vol. 1 No. 5 May: 15.

SEARLE C 1988 : Aspects of selected nursing issues. Durban: Butterworths.

SEARLE C \& PERA S 1995 : Professional practice: a South African nursing perspective. Durban: Butterworths.

SMITH P 1992 : The emotional labour of nursing: How nurses care. London: The MacMillan Press Ltd.

SOUTH AFRICA 1995 : The Labour Relations Act (Act 66 of 1995). Pretoria: Government Printers.

SOUTH AFRICA 1997 : Batho Pele White Paper on Transforming Public Service Delivery. Pretoria: Government Printer.

STYLES M 1982 : On nursing: Toward a new endowment. St Louis: The CV Mosby Company.

UYS L 1992 : Ethical arguments for and against strike. Nursing RSA. Vol. 17. No. 3. March: 32.

VAN TONDER S 1992 : The influence of strikes on rights. Nursing RSA. Vol. 17. No. 3. March: 30-31. 